\title{
Superior mesenteric artery blood flow and gastric emptying in humans and the differential effects of high fat and high carbohydrate meals
}

Departments of
Physiology and
Pharmacology
M B Sidery
I A Macdonald
and Medical Physics,
University of Nottingham
Medical School,
Nottingham
P E Blackshaw
Correspondence to:
Dr M B Sidery, Department of
Physiology and Pharmacology,
University of Nottingham
Medical School, Nottingham
NG7 2UH.
Accepted for publication
17 June 1993

Departments of Physiology and Pharmacology I A Macdonald

and Medical Physics, Medical School, Nottingham

Correspondence to: Dr M B Sidery, Department of Physiology and Pharmacology, Medical School, Nottingham

Accepted for publication 17 June 1993

\author{
M B Sidery, I A Macdonald, P E Blackshaw
}

\begin{abstract}
This study was designed to determine if the differential effect of high fat and high carbohydrate meals on mesenteric blood flow is a result of changed gastric emptying rate. Eight healthy men were studied twice. Superior mesenteric artery blood flow (Doppler ultrasound) was measured before and after a $2.5 \mathrm{MJ}$ meal (either $74 \%$ of the energy as carbohydrate or $71 \%$ as fat). Emptying of meals was followed by $\gamma$-scintigraphy. The pattern of the superior mesenteric artery blood flow response was different after the two meals (interaction effect $\mathbf{p}<\mathbf{0 . 0 0 1}$ analysis of variance), with a far more sustained response after fat. The time by which half the meal had emptied $\left(t_{50}\right)$ was also significantly greater after fat $(\mathbf{p}<0.02)$. Superior mesenteric artery blood flow corresponding to $t_{50}$ was $449 \mathrm{ml} / \mathrm{min}$ after carbohydrate and $592 \mathrm{ml} / \mathrm{min}$ after fat. There was a significant curvilinear relation between the superior mesenteric artery blood flow response and gastric emptying after carbohydrate $\left(r^{2}=0.94\right)$ and no relation at all after fat. This study confirms the finding that ingestion of meals with a high fat content slows gastric emptying compared with meals with a high carbohydrate content in healthy volunteers. A more sustained mesenteric hyperaemia was also recorded after the fat meal compared with the carbohydrate meal. The relation, however, between the volume of meal remaining in the stomach and the mesenteric response was considerably different after the two meals. Further study is required to elucidate the mechanism behind the vascular responses recorded in the mesenteric bed after food in humans.

(Gut 1994; 35: 186-190)
\end{abstract}

The rate at which the contents of the stomach pass through the pylorus to the small intestine is determined by the composition of the chyme. Fat content, ${ }^{1}$ amino acid content,${ }^{2}$ osmolality, ${ }^{3}$ $\mathrm{pH},{ }^{4}$ meal volume, ${ }^{5}$ and energy content ${ }^{6}$ all affect the rate at which the stomach empties. Control of emptying is complex, with possible mediators including gastrointestinal peptides ${ }^{78}$ and reflex pathways involving extrinsic neurones. ${ }^{3}$

The rise in mesenteric blood flow after the ingestion of food in humans is rapid. Early invasive studies showed $60 \%$ increases in superior mesenteric artery flow within five minutes of completion of a meal. ${ }^{9}$ The pattern of the mesenteric response is dependent upon the composition of the meal ingested. Ingestion of fat leads to a more delayed but larger mesenteric response compared with carbohydrate. ${ }^{10-12}$ The number of investigations, however, of the mesenteric responses to food in humans is limited and no study has continued for more than 90 minutes postprandially. ${ }^{10}$ Mesenteric hyperaemia is thought to be associated with nutrient absorption in the gut ${ }^{13}$ and intragastric placement of food in animal studies has shown that hyperaemia can be localised to those gut segments exposed to predigested food. ${ }^{14}$

This study investigates the effect of high fat and high carbohydrate meals of the same energy content on the mesenteric response in humans in relation to the rate of gastric emptying.

\section{Subjects and methods}

Eight healthy men (22-27 years, body mass index $21 \cdot 8-24.8 \mathrm{~kg} / \mathrm{m}^{2}$ ) were recruited for the study. The subjects were screened for any cardiovascular or gastrointestinal disorder and none were smokers. The subjects gave written, informed consent to take part in the study, which was approved by the University of Nottingham Medical School ethical committee and the British Department of Health (ARSAC). The subjects were studied on two occasions, with the experiment starting at the same time on both occasions (1230 pm) to avoid the effect of diurnal variation on gastric emptying rate. ${ }^{15}$ The subjects were requested to eat a light breakfast before 800 am (caffeine free) and to avoid strenuous exercise on the morning of the studies. On entering the laboratory low energy radioactive anatomical markers (technetium-99m ${ }^{99 m} \mathrm{Tc}$ ) were attached to the surface of the skin anteriorly and posteriorly. When visualised on the computer screen linked to the gammacamera, these prevent inaccurate repositioning of the subject and also make any subject movement during data acquisition obvious. Once the markers were in place the subjects rested supine for 30 minutes.

After the rest period, fasted superior mesenteric artery blood flow velocity measurements were made using transcutaneous Doppler ultrasound with a $5 \mathrm{MHz}$ curvilinear pulsed wave imaging system with a $2 \mathrm{MHz}$ offset Doppler. ${ }^{12}$ On occasions the vessel was obscured by the presence of abdominal gas, particularly in the postprandial stage of the study. In such cases, the angle at which the subject rested was carefully adjusted to a semisupine position, having the effect of displacing the gas and permitting measurement to proceed. The subject was then immediately returned to the supine position. The angle of insonation was recorded and used to convert the Doppler shift values $(\mathrm{kHz})$ into blood flow velocity $(\mathrm{cm} / \mathrm{s})$. Care was taken to 
ensure that wherever possible the same angle of insonation was used in each subject (mean angle of insonation was $29^{\circ}$, range $18-38^{\circ}$ ). Error brought into the flow calculation due to an angle of insonation of $29^{\circ}$ would be in the range of 4-5\%. ${ }^{16}$ Doppler signals were recorded, and analysed by spectral analysis using a 2 channel analyser that displays forward and reverse signals separately. Eighty separate frequency measurements were made in the forward and the reverse channel and the input spectrum sampled at $5 \mathrm{~ms}$ intervals. Maximum pulse repetition frequency was $5 \mathrm{MHz}$. Recordings were made with the subjects' breath held in mid inspiration, and stored on video tape. Mean values of time averaged mean velocity (TAM calculated using the intensity weighted mean frequency) and peak systolic velocity were taken from at least 10 Doppler waveform complexes. The time averaged mean velocities were used in the calculation of absolute flow ( $\mathrm{ml} / \mathrm{min})$. Peak systolic velocity is the maximal velocity reached during each cardiac cycle, and occurs during systole.

The manually operated calipers used to estimate vessel diameter on the Duplex ultrasound machine give diameter readings with an accuracy of $1 \mathrm{~mm}$ and cannot resolve changes during the cardiac cycle. At each time point the diameter was determined from a mean of four measurements of the proximal portion of vessel.

After the fasted measurements the subjects sat up and ingested, in a randomised order, either a high carbohydrate or high fat meal. Both meals had a total energy content of $2.5 \mathrm{MJ}$. They were based on meals of chicken, gravy, potato, carrots, and banana custard or ice cream and cream. The percentage energy as carbohydrate was $74 \%$ in the high carbohydrate meal and $14 \%$ in the high fat. The energy content as fat was respectively 7 and $71 \%$. Sodium and potassium contents were around $330 \mathrm{mg}$ and $1650 \mathrm{mg}$ in the two different meals. ${ }^{17}$ Volume occupied by the meals did differ, with the high carbohydrate meal being approximately $600 \mathrm{ml}$ compared with the high fat meal which was approximately 350 $\mathrm{ml}$. The weight of the high carbohydrate meal was $581 \mathrm{~g}$ and the high fat $325 \mathrm{~g}$.

The vegetables and gravy were mashed and $300 \mathrm{mg}$ of amberlite ion exchange resin BDH (IRA 416) (milled to form a coarse mixture of variable diameter particles), were mixed with the mash. The particles were previously labelled by addition of $\mathrm{TcO}^{-4}$ calculated to be $3 \mathrm{MBq}$ at the time of dosing. No attempt was made to selectively label any single component of the meals and it was assumed that the labelled particles would be distributed throughout the stomach contents once ingested. Techniques are available that permit radioisotopic labelling of fat, ${ }^{18}$ but the aim of this study was to investigate the effect of fat on the emptying of the entire contents of the stomach.

No longer than 15 minutes were taken to eat the meal on any occasion. Apart from one subject who could not complete the high carbohydrate meal (about $10 \%$ remained uneaten), no subject voiced any feelings of discomfort or nausea after either the high fat or high carbohydrate meals and the opinion tended to be that the high carbohydrate meal caused a greater feeling of fullness compared with the fat meal. Inclusion of the data from the subject who failed to complete the one meal had no effect on the overall results.

On completion of the meal, the subjects immediately returned to the supine position and imaging was started. Although the tendency to redistribute blood away from the mesenteric bed during exercise is less in the postprandial state, ${ }^{19}$ movement of the subjects over the remainder of the experimental period was kept to a minimum. Posture has an effect on the rate of gastric emptying, ${ }^{20}$ and in this study the subjects remained quiescent and in the supine position.

Gastric emptying data were acquired with 30 second anterior and posterior images of the stomach $^{21}$ every 20 minutes using a IGE maxicamera 11 gammacamera fitted with a low energy general purpose collimator. The gammacamera was linked to a dedicated nuclear diagnostics nuclear medicine computer system. Regions of interest were created around the computer generated image of the stomach for both anterior and posterior images, and counts recorded. The geometric mean of the anterior and posterior measurements was calculated and counts were corrected for background radiation and isotope decay.

Data were collected every 20 minutes, with radioisotope data acquisition being followed by superior mesenteric artery blood flow velocity measurements until at least $70 \%$ of the meal had left the stomach or 180 minutes had passed since ingestion of the meal. After this time the subjects tended to become restless.

\section{STATISTICAL ANALYSIS}

Statistical analysis of the results was performed by two way analysis of variance with repeated measures (ANOVA) using the package BMD.P (BMDP Statistical Software, Los Angeles, California). A paired $t$ test was used for comparison of the $t_{50}$ data. Volume of food remaining in the stomach $(\mathrm{ml})$ was calculated by multiplying the percentage of the meal remaining in the stomach by the total volume of the meal.

Data are presented in the figures as means (standard errors of the means) except where shown. The data reported in the text are absolute values with standard errors in brackets, and changes from baseline with the $95 \%$ confidence intervals of the change unless stated otherwise.

\section{Results}

\section{SUPERIOR MESENTERIC ARTERY BLOOD FLOW}

Fasted superior mesenteric artery blood flow was $346 \mathrm{ml} / \mathrm{min}(27 \cdot 1)$ before the high carbohydrate meal and $351 \mathrm{ml} / \mathrm{min}(20.4)$ before the high fat meal. A peak blood flow of $611 \mathrm{ml} / \mathrm{min}(80)$ was achieved 20 minutes after ingestion of the high carbohydrate meal (95\% confidence intervals of the increase above baseline 106 to $424 \mathrm{ml} / \mathrm{min}$ ). In contrast, a peak blood flow of $715 \mathrm{ml} / \mathrm{min}$ (49) was reached 40 minutes after fat $(95 \% \mathrm{CI}$ of the increase above baseline 237 to $491 \mathrm{ml} / \mathrm{min}$ ). The peak blood flows recorded after the two meals were not significantly different (Fig 1). 

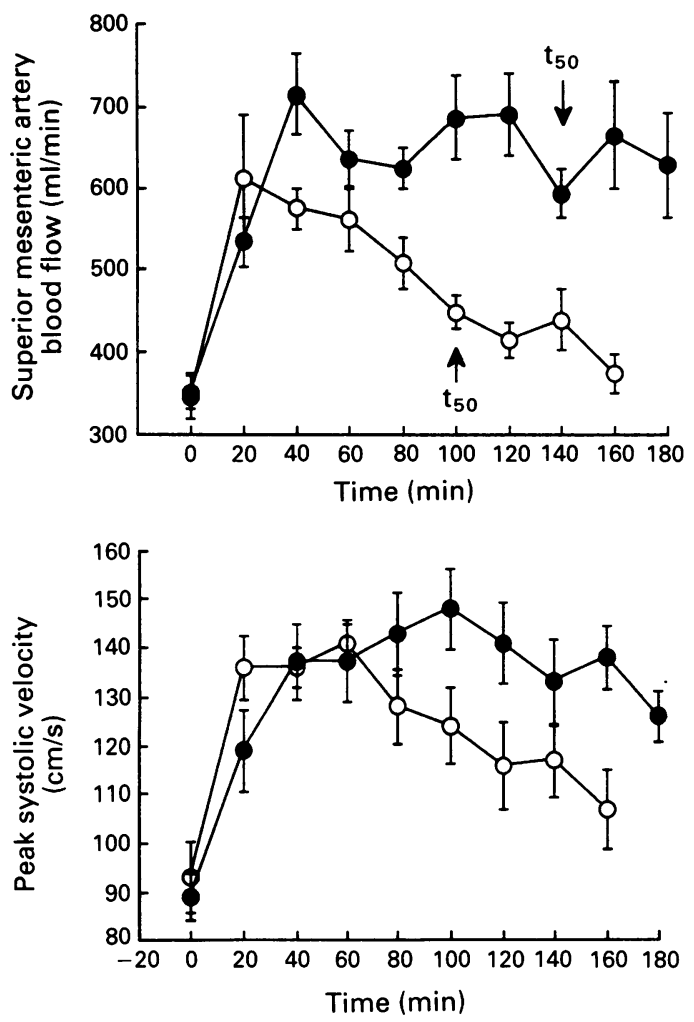

Figure 1: Superior mesenteric artery blood flow $(\mathrm{ml} / \mathrm{min})$ and peak systolic velocity $(\mathrm{cm} / \mathrm{s})$ during the baseline period (time 0) and after the ingestion of the high carbohydrate $(\bigcirc)$ and high fat (O) meals. Values are means with their standard errors representd by vertical lines. The pattern of blood flow response and peak systolic velocity was significantly different (interaction effect $p<0.001$, ANOVA), with blood flow returning to a value not significantly different from baseline 160 minutes after the carbohydrate meal and flow remaining significantly raised throughout the experimental period after the high fat meal.

After the early blood flow peak with carbohydrate, superior mesenteric artery blood flow began to fall towards fasted values, and was not significantly different from baseline 160 minutes postprandially. In contrast, mesenteric blood flow was still $277 \mathrm{ml} / \mathrm{min}$ above pre food values 180 minutes after fat $(95 \% \mathrm{CI}$ of the increase 144 to $410 \mathrm{ml} / \mathrm{min}$ ). The pattern of the mesenteric blood flow response was significantly different after the two meals (interaction effect $\mathrm{p}<0.001$, ANOVA).

PEAK SYSTOLIC VELOCITY

Peak systolic velocity in the fasted state was 93 $\mathrm{cm} / \mathrm{sec}(7 \cdot 3)$ before the high carbohydrate meal

Figure 2: Gastric emptying after the ingestion of the high carbohydrate $(\bigcirc)$ and high fat (O) meals, shown as a percentage of the measurements made at the moment that the meals were finished $($ time $=0)$. There was a significant difference in the pattern of response after the two meals (interaction effect $p<0.05$, ANOVA). $t_{50}$ after the carbohydrate $(C)$ and fat $(F)$ meals are shown as a dotted line.

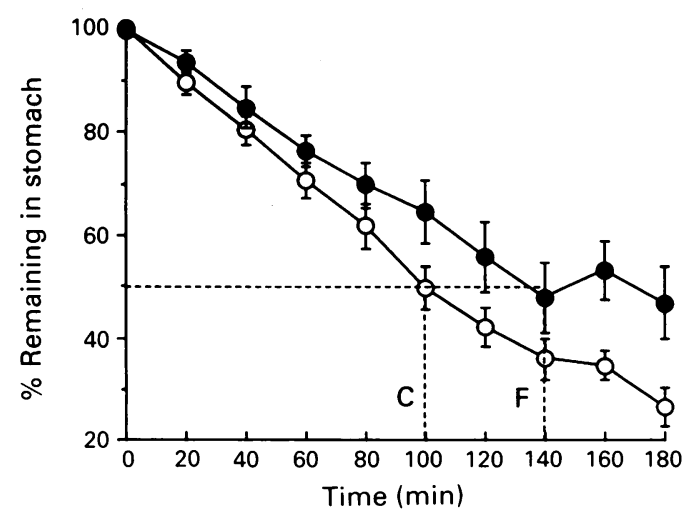

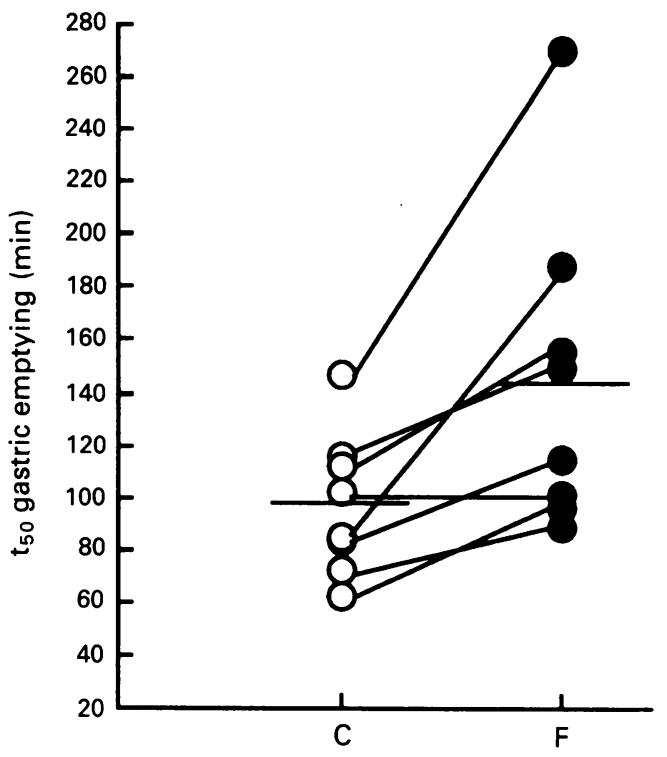

Figure 3: Shows the individual $t_{50}$ data after the ingestion of the high carbohydrate $(C)(O)$ and high fat $(F)(O)$ meals. $t_{50}$ was greater after the high fat meal compared with the high carbohydrate meal in all but one of the subjects. The mean $t_{50}$ values after the two meals (shown as horizontal bars) are significantly different $(p<0 \cdot 02)$.

and $89 \mathrm{~cm} / \mathrm{sec}(4 \cdot 8)$ before the high fat meal. The highest peak flow velocity after the high carbohydrate meal was reached at 60 minutes (141 $\mathrm{cm} / \mathrm{s}(4 \cdot 6))(95 \% \mathrm{CI}$ of the increase above baseline 33.8 to $61 \cdot 2 \mathrm{~cm} / \mathrm{s}$ ), and after the high fat was $148 \mathrm{~cm} / \mathrm{s}(8 \cdot 3)$ at 100 minutes $(95 \% \mathrm{CI}$ of the increase above baseline 37.6 to $81 \cdot 4 \mathrm{~cm} / \mathrm{s}$ ). There was no statistical difference between the maximum peak systolic velocities after the two meals. There was a significant difference in the pattern of change after the two meals (interaction effect $\mathrm{p}<0.001$, ANOVA) (Fig 1).

\section{GASTRIC EMPTYING}

No substantial lag phase between ingestion and gastric emptying was seen after either meal - that is, emptying had started within the first 20

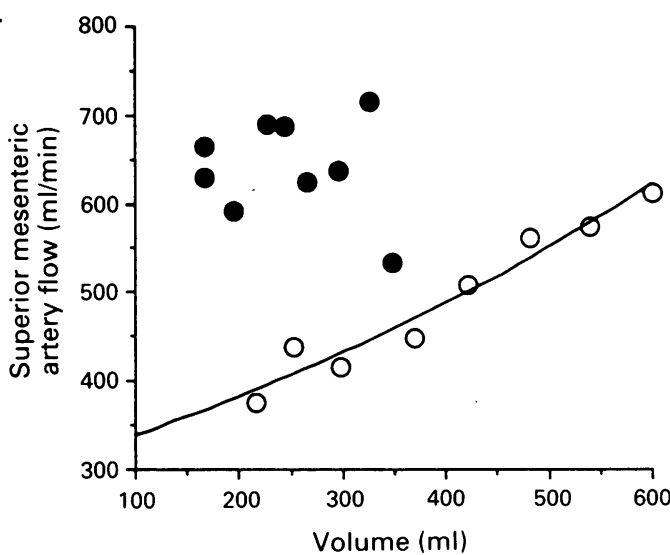

Figure 4: Stomach contents and superior mesenteric artery blood flow after the two meals. Each point represents the mean superior mesenteric artery blood flow ( $\mathrm{ml} / \mathrm{min})$ plotted against the mean volume of the meal remaining in the stomach $(\mathrm{ml})$ at the time point (calculated from the gastric emptying data). Note the different starting volumes for the two meals. The relation between blood flow and volume is described by an exponential line after the high carbohydrate meal $(O)\left(r^{2}=\right.$ $0.94)$. There is no relation between the volume of the meal in the stomach and superior mesenteric artery blood flow after the high fat meal (O). 
minutes. There was a significant difference in the pattern of emptying after the two meals (interaction effect $\mathrm{p}<0.05$, ANOVA) (Fig 2). There was a significant difference between the times at which $50 \%$ of the meals had left the stomach $\left(t_{50}\right)$, with $t_{50}$ after the carbohydrate meal $=97 \cdot 3$ minutes (9.7) and $t_{50}$ after the high fat meal= 145.4 minutes $(21 \cdot 6)(t$ test $\mathrm{p}<0.02)$ (Fig 3$)$.

Superior mesenteric artery blood flow at these time points was $449 \mathrm{ml} / \mathrm{min}$ after the high carbohydrate meal and $592 \mathrm{ml} / \mathrm{min}$ after the fat ( $95 \%$ CI of the difference 75 to $212 \mathrm{ml} / \mathrm{min}$ ) (Fig 1). There is a relation between the volume of the meal remaining in the stomach and superior mesenteric artery blood flow after the high carbohydrate meal (Fig 4). The relation is described by an exponential line $\left(r^{2}=0 \cdot 94\right)$. There seems to be no relation between mesenteric blood flow and volume remaining in the stomach for the high fat meal.

\section{Discussion}

In this study there was a significant difference between the $t_{50}$ of the high fat and high carbohydrate meals. No attempt was made to specifically label any single component of the meals and this result confirms findings that fat does slow the rate of gastric emptying. ${ }^{122}$ The delay that exists between ingestion and emptying is referred to as the lag phase. ${ }^{23}$ This phase is short in length (approximately eight minutes), with fat increasing the lag period, possibly as a result of the redistribution of the stomach contents back to the proximal stomach. ${ }^{22}$ In this study a lag phase was not seen, possibly because of the discontinuous nature by which gastric emptying data were acquired, ${ }^{23}$ and it is feasible that this transient phase was missed.

The Hunt and Stubbs hypothesis states that gastric emptying of liquid meals is controlled by nutrient density (total $\mathrm{kcal} / \mathrm{g}$ or $\mathrm{ml}$ of food), with the degree of slowing directly related to the nutrient density of the stomach contents entering the duodenum. ${ }^{5}$ In our investigation the two study meals were of identical energy content. $t_{50}$ after the high carbohydrate meal was 97 minutes and nutrient density $2.5 \mathrm{MJ} / 581 \mathrm{~g}=4.3 \mathrm{~kJ} / \mathrm{g}$. Nutrient density of the high fat meal is $7 \cdot 7 \mathrm{~kJ} / \mathrm{g}$. According to the above hypothesis, $\mathrm{t}_{50}$ after the high fat meal should be 151 minutes, which is surprisingly similar to the recorded $t_{50}$ of 145 minutes.

Increasing weight of solid meals increases the absolute rate of emptying. It has been shown, however, that with meals of the same energy, a $300 \%$ increase in meal weight increases emptying rate by $388 \%$, while a $304 \%$ increase in energy content reduces emptying rate by $43 \%$ in meals of the same weight. ${ }^{6}$ In our study, the meals consisted of similar food stuffs, with the high fat meal weighing $325 \mathrm{~g}$ and the high carbohydrate meal weighing $581 \mathrm{~g}$. It is therefore possible that the delay in emptying seen after the high fat meal in this study is overestimated as a consequence of the difference in weight between the two meals.

The pattern of superior mesenteric artery blood flow response after ingestion of the two meals was significantly different. This confirms findings of a similar nature after both solid ${ }^{12}$ and liquid meals. ${ }^{10}$ The onset of the mesenteric response is slightly delayed after a high fat compared with a high carbohydrate meal. ${ }^{112}$ In this study there was no significant difference between the size of the mesenteric response 20 minutes after the two meals, although the peak value after the high fat meal occurred later.

In this study there was no significant difference between maximal hyperaemia after the two meals. Similar maximal flows after meals high in fat and high in carbohydrate have been shown by some $^{11}$ and not others. ${ }^{1012}$ All studies are in agreement that the mesenteric blood flow response is more prolonged after fat meals compared with carbohydrate, but postprandial measurements have not been continued beyond 90 minutes. ${ }^{10}$ In this study mesenteric blood flow was $79 \%$ above baseline 180 minutes after the fat meal. In contrast, after the high carbohydrate meal blood flow had returned to baseline values between 140 and 160 minutes. This may in part be accounted for by the delayed emptying of fat seen. Our results also suggest that fat is a more powerful stimulant of mesenteric blood flow than carbohydrate - that is, joule for joule, fat incurs a greater hyperaemia than carbohydrate.

It seems that there may be a relation between the rate of emptying of food from the stomach and the blood flow response. This would confirm reports that increased blood flow in the gut is associated with the absorption of nutrients. ${ }^{13}$ Calculation (from gastric emptying data) of the volume of food remaining in the stomach (Fig 4), however, shows a relation between volume emptied and mesenteric blood flow only after the high carbohydrate meal. No such relation exists after the high fat meal.

The role of gastrointestinal peptides in the vascular changes seen in the mesenteric bed on food ingestion is unclear. Gastric inhibitory polypeptide would respond to both meals, but does not have vasoactive properties. Pancreatic polypeptide probably responds to both meals, in particular the high fat meal. Neurotensin, the tachykinins, vasoactive intestinal polypeptide, and insulin will all respond to different degrees to the two meals. Some of these peptides secreted have vasoactive properties. ${ }^{24}$ Of the peptides that have been investigated more fully, however, there is evidence that at physiological concentrations they play only an indirect part in the vascular changes associated with food ingestion. ${ }^{25} 26$ In this study no measurements were made of plasma concentrations of gastrointestinal peptides after the two meals.

In conclusion, this study has confirmed reports that fat slows the rate at which meals leave the stomach. Considering the effect of the weight of meals on gastric emptying, ${ }^{6}$ the effect of fat on gastric emptying may have been overestimated. This study also confirms findings that the mesenteric response after the ingestion of a high fat meal is slightly delayed and is more prolonged than after a meal low in fat content. Fat is also a more potent stimulator of mesenteric blood flow compared with carbohydrate. Finally, the relation between gastric emptying of a meal and the mesenteric response to that meal is different for meals of different composition. Further studies are necessary to clarify the 
mechanisms by which these changes are mediated.

The authors would like to thank Dr Alan Perkins for his advice on $\gamma$-scintigraphy and Dr Robin Spiller as holder of the ARSAC licence. We would also like to thank Christine Burton for preparing the meals.

This study was supported by a Wellcome Trust Research Project Grant.

1 Hunt JN, Knox MT. A relationship between the chain length of fatty acids and the slowing of gastric emptying. F Physiol (Lond) 1968; 194: 327-36.

2 Stephens JR, Woolson RF, Cooke AR. Effects of essential and non-essential amino acids on gastric emptying in the dog Gastroenterology 1975; 69: 920-7.

3 Forster ER, Green T, Dochray GT. Efferent pathways in the reflex control of gastric emptying in rats. Am f Physiol 1991; 260: G49-54.

4 McHugh PR, Moran TH. Calories and gastric emptying: a regulatory capacity with implications for feeding. Am $\mathcal{F}$
Physiol 1979; 236: R254-60.

5 Hunt JN, Stubbs DF. The volume and energy content of meals as determinants of gastric emptying. $\mathcal{F}$ Physiol (Lond) 1975; 245: 209-25.

6 Moore JG, Christian PE, Brown JA, Brophy C, Datz F, Taylor $A$, et al. Influence of meals on weight and caloric content on A, et al. Influence of meals on weight and caloric content on gastric

7 Green T, Dimaline R, Peikin S, Dockray G. Action of cholecystokinin antagonist $\mathrm{L} 364,718$ on gastric emptying in the rat. Am F Physiol 1988; 255: G685-9.

$8 \mathrm{McC}$ allum RW. Motor function of the stomach in health and disease. In: Sleisenger MH, Fordtran JS, eds. Gastrointestinal disease: pathophysiology, diagnosis, management. Philadelphia: W B Saunders, 1989: 675-713.

9 Norryd C, Dencker H, Lunderquist A, Olin T, Tylen U. Superior mesenteric blood flow during digestion in man. Acta Chir Scand 1975; 141: 197-202.

10 Moneta GL, Taylor DC, Helton WS, Mulholland MW, Strandness DE Jr. Duplex ultrasound measurement of postprandial intestinal blood flow: effect of meal composition. Gastroenterology 1988; 95: 1294-301.

11 Qamar MI, Read AE. Effects of ingestion of carbohydrate, fat, protein and water on the mesenteric blood flow in man. protein and water on the mesenteric
Scand F Gastroenterol 1988; 23: 26-30.
12 Sidery MB, Macdonald IA, Cowley AJ, Fullwood LJ. Cardiovascular effects of high fat and high carbohydrate meals in young subjects. Am F Physiol 1991; 261: H1430-6.

13 Qamar MI, Read AE, Mountford R. Increased superior mesenteric blood flow after glucose but not after lactulose ingestion. $O \mathcal{F}$ Med 1986; 60: 893-6.

14 Chou CC, Hsiesh CP, Yu YM, Kvietys P, Yu LC, Pittman R, et al. Localisation of mesenteric hyperaemia during digestion in dogs. Am $\mathcal{F}$ Physiol 1976; 230: 583-9.

15 Goo RH, Moore JG, Greenberg E, Alazraki NP. Circardian variation in gastric emptying of meals in humans. Gastrovariation in gastric emptying

16 Gill RW. Measurement of blood flow by ultrasound. Ultrasound Med Biol 1975; 11: 625-41.

17 Potter JF, Heseltine D, Hartley G, Matthews J, Macdonald IA, et al. Effects of meal consumption on the postprandial blood pressure, catecholamine and insulin changes in elderly subjects. Clin Sci 1989; 77: 265-72.

18 Cunningham KM, Baker RJ, Horowitz M, Maddox AF Edelbroek MAL, Chatterton BE. Use of technetium - $99 \mathrm{~m}$ v) thiocyanate to measure gastric emptying of fat. $7 \mathrm{Nucl}$ Med 1991; 32: 878-81.

19 Waaler BA, Eriksen M, Janbu T. The effect of a meal on cardiac output in man at rest and during moderate exercise. Acta Physiol Scand 1990; 140: 167-73.

20 Moore JG, Datz FL, Christian PE, Greenberg E, Alazraki N. Effect of body posture on radionuclide measurements of gastric emptying. Dig Dis Sci 1988; 33: 1592-5.

21 Hardy JG, Perkins AC. Validity of the geometric mean correction in the quantification of whole bowel transit. correction in the quantification of

22 Houghton LA, Mangall YF, Read NW. Effect of incorporating fat into a liquid test meal on the relation between intragastric distribution and gastric emptying in human volunteers. Gut 1990; 31: 1226-9.

23 Christian PE, Datz FL, Moore JG. Confirmation of short solid-food lag phase by continuous monitoring of gastric emptying. F Nucl Med 1991; 32: 1349-52.

24 Thulin L, Samnegard H. Circulatory effects of gastrointestina hormones and related peptides. Acta Chir Scand 1978; 144 (suppl 482): 73-4.

25 Fara JW, Rubinstein EH, Sonnenschein RR. Intestinal hormones in mesenteric vasodilation after intraduodenal hormones in mesenteric vasodilation afte

26 Premen AJ, Kvietys PR, Granger DN. Postprandial regulation of intestinal blood flow: role of gastrointestinal hormones. Am $\mathcal{F}$ Physiol 1985; 249: G250-5. 